\title{
Design and Analysis of Proximity Coupled Circularly Polarised Micro Strip Antenna with Uneven Parallel Slots
}

\author{
Shivendra Vikram Singh ${ }^{1}$, Abhinav Bhargav ${ }^{2}$ \\ (Scholar) $)^{l}$, Department Of Electronics \& Communication, G.G.I.T.M., Bhopal, India \\ (Asst. Prof. $)^{2}$, Department Of Electronics \& Communication, G.G.I.T.M., Bhopal, India
}

\begin{abstract}
In the present paper, a wideband circularly polarized micro strip antenna is designed for application in wireless local area network (WLAN). The proposed antenna is L strip fed proximity coupled circular micro strip antenna where the radiating patch is loaded by parallel slots of unequal length. The structure is investigated using circuit theoretic approach and simulated using IE3D simulation software. The patch is designed on a thick substrate of thickness of $13 \mathrm{~mm}$ and provides wide band operation. The circular polarization is achieved by cutting two asymmetric parallel to linear axis of feed, slots on circular radiating patch to produce orthogonal modes. The simulation results for input impedance, VSWR, radiation pattern, directivity and gain are presented. Bandwidth is found to be dependent on length of horizontal part of L-strip as well as impedance matching at feed location. A bandwidth of up to $97.72 \%$ is enhanced (for VSWR $\leq 2$ ) for $L i=0.102 \lambda o$ and $h 2=0.201 \lambda$. The right circularly polarisation was achieved for two bands with $6 \%$ and $7 \%$ axial ratio band width at resonance frequency.
\end{abstract}

Index Terms: L-strip feed, proximity coupled, inset slot, circular polarisation, wideband,

\section{Introduction}

Micro strip patch antennas have been commonly used mainly since they are lightweight, compact and cost effective. The input impedance of these antennas depends on their geometrical, dimensions, the physical properties of the materials involved, the feed type and location. Therefore, a subset of antenna parameters can be accustomed to achieve the "best" geometry for matching of a particular resonance. The inset-fed micro strip antenna offers a method of impedance control with a planar feed configuration $[4,5]$. Micro strip patch is designed such that its pattern maximum is normal to the patch (broadside radiator). This is accomplished through proper choice of the mode (field configuration) of excitation beneath the patch. The ones that are most desirable for antenna performance are thick substrates whose dielectric constant is in the lower end of the range. This is because they provide better efficiency. Circular micro strip patch configurations are the one of most common because of their simplicity of analysis, fabrication, and their smart radiation characteristics, especially the low cross-polarization radiation which makes it good for circular polarisation (CP). The BW of CMSA is increased by cutting the slot at an appropriate position inside the patch and these slot cut CMSAs are optimized on substrates with thickness more than $0.09 \lambda \mathrm{o}$, the proximity feeding as well as L-probe feeding has been used $[4,9,16]$. In proximity feeding, a coupling strip is placed below the radiating patch and through the electromagnetic coupling linking patch and strip, a broadband response is realized. Proximity coupling offers the advantage of low cross polarization levels but, at the same time this technique suffers from inherently low coupling levels and difficulties in impedance matching. Due to this, often relatively low bandwidths are achieved using this feed. This problem can be solved up to a fine extent by using a slot in the ground plane. The slot in the ground plane helps to couple more power to the patch [13]. The size of the slot can be used for impedance matching. And with this wider bandwidths can be achieved. It has been shown in [1] that impedance bandwidth as high as $21 \%$ can be accomplished using this kind of configuration.

Circularly polarized antennas with low profile, small size, light weight, and high impedance bandwidth and axial ratio bandwidth are on high demand for example in mobile satellite communications. In the topical years, the circular polarization is used in current wireless communication system since they are rather insensitive to device orientation [10] than for linearly polarized antennas. The operation opinion of CP antenna is to carry out two orthogonal field components with equal amplitude but in phase quartered. A slot can be perturbed to excite two degenerate orthogonal modes for generation of $\mathrm{CP}$ fields. Perturbation can be made by shorting an annular slot [11], rectangular bent slot [12]. Circularly polarization can also be achieved by designing a corner truncated square patch, a circular patch with cross slot, or micro strip fed proximity couple ring design [13-14], a single probe fed stacked micro strip antenna [15] and L-probe fed with cross slots [16]. A single fed design normally provides narrow bandwidth.

In this paper, various reported broadband designs of L-probe fed RMSA, rectangular slot cut CMSA are further used for their optimized designs, the formulation for total L-probe length in terms of operating wavelength of the resonance frequency of the radiating patch. The total L-probe length was found to be around 
quarter wave in length at the patch resonance frequency. Micro strip antenna with a narrowband and a wide band characteristic is presented where the circular radiating patch is loaded by cutting inset look like slot of equal arms length with established rectangular slot [20]. L-strip proximity coupled slot loaded circular micro strip antenna is investigated using cavity model and circuit theory approach. The cavity is used to pay for effective coupling to the patch with a thick substrate. The circular polarization is attained by cutting parallel slots of equal lengths on circular radiating patch which adds and produces orthogonal modes. Adding a slot helps in improving the coupling level and the bandwidth of the antenna, but at the same time this also adds to the back radiation due to the slot as the slot radiates bi directionally. A slot over feed line is made so back radiation could be countered. The proposed antenna has bandwidth about $97.8 \%$ (Return loss $-10 \mathrm{~dB}$ ) and axial ratio bandwidth is about $13.3 \%$ (below $3 \mathrm{~dB}$ ). Results show that proposed antenna has wide impedance bandwidth and very good axial ratio bandwidth. The proposed study was carried out using IE3D software [18] and to validate the simulated results, measurements were carried out using finite square ground plane of six times to resonance wavelength.

\subsection{L-Strip Fed CMSA}

\section{Antenna Design And Geometry}

Top view and side view of the designed antenna is shown in fig. 1 in which parallel slots of unequal length is integrated. The basic design parameters of the proposed antenna are same as taken by Y. X. Guo, K. M. Luk and K. F. Lee [11] for comparison purpose. The radius of patch (a) is $17 \mathrm{~mm}$, total height $(\mathrm{H})$ of substrate is $13 \mathrm{~mm}$ which is altered from original CMSA design [11], and dielectric constant is $1.07\left(\varepsilon_{1}=\varepsilon_{2}=\varepsilon_{3}\right.$ foam layer). The parameters, new for the design are height of micro strip feed ( $\mathrm{h} 1=1.6 \mathrm{~mm} \approx 0.02 \lambda_{\mathrm{o}}$ ), height of L-strip $(\mathrm{h} 2=9.8 \mathrm{~mm} \approx 0.125 \lambda \mathrm{o})$ and gap between circular patch and horizontal part of L-strip (h3=1.6 $\left.\mathrm{mm} \approx 0.02 \lambda_{\mathrm{o}}\right)$. The design frequency of the antenna is $5.74 \mathrm{GHz}\left(\lambda_{\mathrm{o}}=60.2 \mathrm{~mm}\right)$. A 50 ohms micro strip line on $1.6 \mathrm{~mm}$ thick substrate was taken to feed the power to L-strip (ws $=5 \mathrm{~mm}$ ). The width and length of L-strip are $5 \mathrm{~mm}$ and $9.5 \mathrm{~mm}(0.121 \lambda \mathrm{o})$ respectively. By using the L-strip, we couple the energy from micro strip line to the patch as the separation between them is too large. The whole structure of L-strip acts as a series LC resonance elements which are connected in series with a parallel RLC resonant element of the patch. The formulas for the calculation of above parameters are given in [18]. The resonant frequency in a circular micro strip antenna is given as [19]

$$
\operatorname{Fr}=\left(\alpha_{\text {np }} C\right) / 2 \pi a e f f \sqrt{\varepsilon r e f f}
$$

Where $\alpha_{n p}$ is the nth zero of the Bessel function of order $p$ and $a_{\text {eff }}$ is the effective radius of the patch and $\mathrm{er}_{\mathrm{eff}}$ is the introduced to take into relation the effect of fringing field. The length of horizontal part of L-strip beneath patch is kept less than quarter wavelength because up to $\lambda_{0} / 4$ length of an open circuited stub, the nature of impedance is capacitive. The capacitance thus introduced is suppressed by the inductance occurring from vertical part of L-strip. Apart from these, a series resistance arises due to finite conductivity of copper used. The expressions of series resistance (Rs) and series inductance (Ls) as given by R. K. Huffman [10] are

$$
\begin{aligned}
& \left.\mathrm{Ls}=.2235\left\{\left(\mathrm{w}_{\mathrm{s}+} \mathrm{t}_{\mathrm{s}}\right) / \mathrm{h}_{2}\right\}+0.5\right]+0.2 \mathrm{~h}_{2}\left[\ln \left\{2 \mathrm{~h}_{2} /\left(\mathrm{w}_{\mathrm{s}+} \mathrm{t}_{\mathrm{s}}\right)\right\} \mathrm{nH}\right. \\
& \mathrm{Rs}=4.13 \mathrm{~h} 2(\mathrm{ws}+\mathrm{ts}) \sqrt{\mathrm{f} \rho / \rho \mathrm{o}}
\end{aligned}
$$

Here Ws is width and ts is thickness of strip in mm, h2 is height of L-strip, $\mathrm{f}$ is operating frequency in $\mathrm{GHz}, \rho$ is specific resistance of the strip and $\rho 0$ is specific resistance of copper. There is a capacitance (Cs1) arising due to vertical electric fields between horizontal part of L-strip and ground plane in series with above Ls and Rs and is calculated as

$$
\mathrm{Cs} 1=\in 0 \in \text { ryows } /(\mathrm{h} 1+\mathrm{h} 2)
$$

Where $\mathrm{y} 0=\mathrm{Li}$ (named as towards y axis progress) is penetration of L-strip into patch $\mathrm{cr}$ is relative dielectric constant and $\varepsilon 0$ is dielectric constant of vacuum. There is a fringing capacitance between open end of L-strip and ground plane (Cf1), between open end of L-strip and patch (Cf2) and between radiating edge of patch and horizontal part of L-strip (Cf2). These capacitances are calculated by estimating extended effective length of $\mathrm{Li}$ strip. The expression of extension in the length of an open ended micro strip line is given by $\mathrm{T}$. $\mathrm{C}$. Edward [11] and is given as

$$
\mathrm{le}=0.412 \mathrm{~h}(\varepsilon \mathrm{e}+0.3)\left(\frac{\mathrm{ws}}{\mathrm{h}}+0.264\right) /(\varepsilon \mathrm{e}-0.258)\left(\frac{\mathrm{ws}}{\mathrm{h}}+0.8\right)
$$

Where $\varepsilon$ e is effective dielectric constant of material buried beneath the micro strip line and ground plane. From T. C. Edward [11] the linked fringing capacitance is calculated as

$$
\mathrm{Cf}=\mathrm{le} \sqrt{\epsilon \mathrm{eff}}_{\mathrm{e}} \mathrm{cZo}
$$




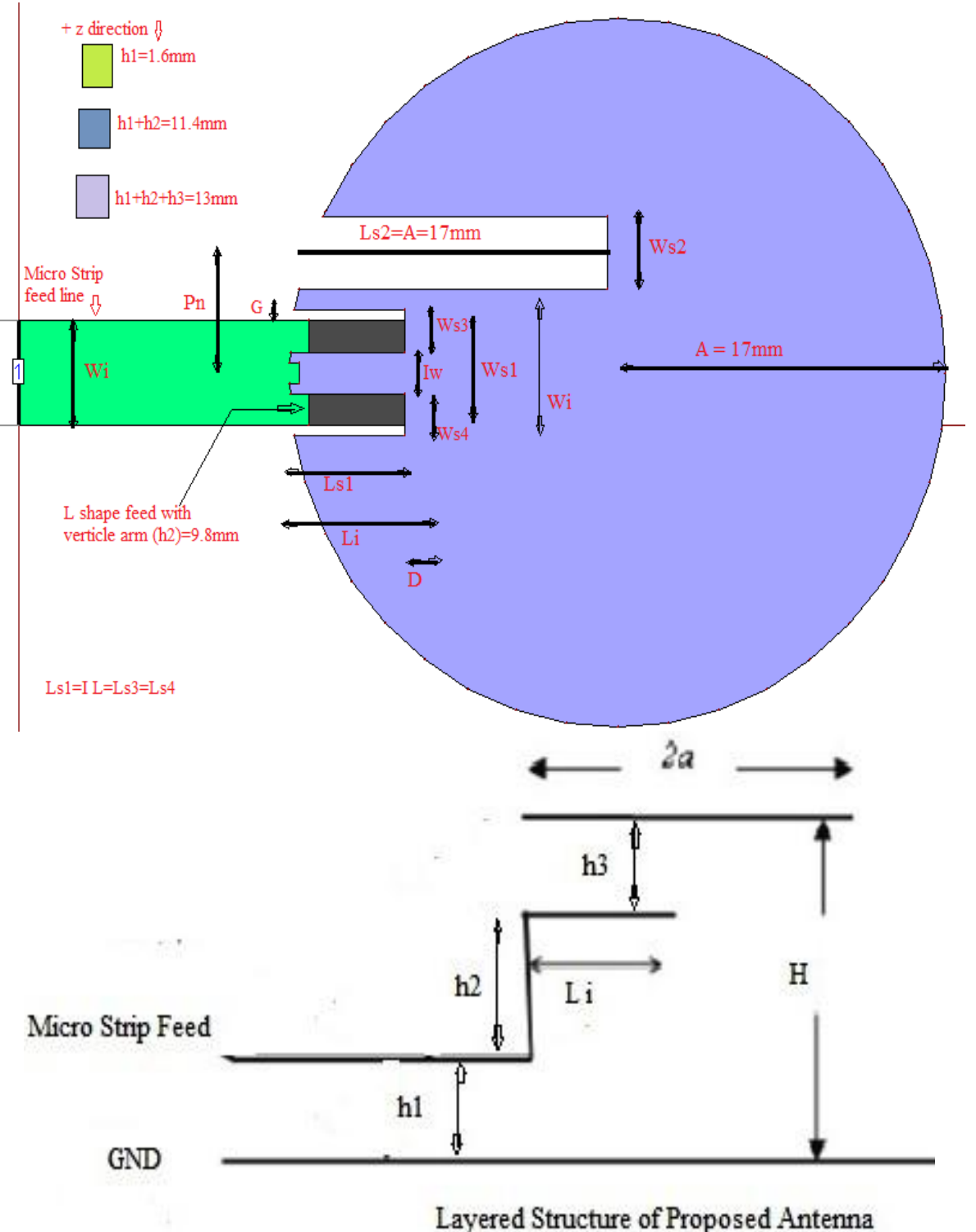

Fig. 1. Geometry of parallel slots loaded L-strip fed proximity coupled circular micro strip antenna (a) Top view (b) Side view

Table I. Design Specification For Cross Slot Loade Disk Patch Antenna

\begin{tabular}{|l|l|}
\hline Substrate Foam & $\varepsilon=1.11$ \\
\hline Radius of circular patch & $(\mathrm{A})=17 \mathrm{~mm}$ \\
\hline Feed width & $(\mathrm{Wi})=6 \mathrm{~mm}$ \\
\hline Feed Length & $(\mathrm{Li})=6.5 \mathrm{~mm}$ \\
\hline Total Substrate thickness & $(\mathrm{H})=13 \mathrm{~mm}$ \\
\hline Gap between microstrip feed and ground plane & $(\mathrm{h} 1)=1.6 \mathrm{~mm}$ \\
\hline Height of L-strip feed & $(\mathrm{h} 2)=9.8 \mathrm{~mm}$ \\
\hline Gap between feed and patch & $(\mathrm{h} 3)=1.6 \mathrm{~mm}$ \\
\hline Relative dielectric constant of substrate material & $(\varepsilon \mathrm{r})=1.08$ \\
\hline Loss tangent & $(\tan \delta)=0.0012$ \\
\hline Slot 1 length & $(\mathrm{Ls} 1)=17 \mathrm{~mm}$ \\
\hline Slot 1 width & $(\mathrm{Ws} 1)=4 \mathrm{~mm}$ \\
\hline Slot displacement from centre & $(\mathrm{Pn})=6 \mathrm{~mm}$ \\
\hline FOR PARAMETRIC STUDY OF RADIATION PATTERN \\
\hline Horizontal length of L-strip feed & $(\mathrm{Li})=3.2 .5,5.25 \mathrm{~mm} .6 .5 \mathrm{~mm}($ optimum $)$, \\
\hline Slot2 at over feed Strip Length & Ls2 $=5.5 \mathrm{~mm}(\mathrm{~A} / 3)(\mathrm{optimum}), 3.4 \mathrm{~mm}(\mathrm{~A} / 5)$, \\
\hline Slot2 at over feed strip Width & Ws2 $=5.5 \mathrm{~mm}, 6 \mathrm{~mm}$ (optimum), gap width side \\
\hline
\end{tabular}


Design and Analysis of Proximity Coupled Circularly Polarised Micro Strip Antenna with...

\begin{tabular}{|l|l|}
\hline Patch movement to left to L feed & $\mathrm{D}(--)=1 \mathrm{~mm}, 2 \mathrm{~mm}$ \\
\hline Patch movement to right to L feed & $\mathrm{D}(+)=1 \mathrm{~mm}, 2 \mathrm{~mm}$ \\
\hline Gap between axis of slot1 to axis of slot2(horizontal) & $\mathrm{Pn}=5 \mathrm{~mm}, 6 \mathrm{~mm}$ (optimum) \\
\hline FOR IMPROVEMENT OF RADIATION PATTERN \\
\hline Slot 3, Slot 4 and Slot 5 width & Ws3 $=\mathrm{Ws} 4=2 \mathrm{~mm}$ and Ws5 = 1mm \\
\hline Slot 3, Slot 4 and Slot 5 length & Ls3 $=\mathrm{Ls} 4=\mathrm{Ls} 5=5.5 \mathrm{~mm}(\mathrm{~A} / 3)($ optimum), \\
\hline Overlap of patch on feed strip(O) & 1 to $3 \mathrm{~mm}, 1.25 \mathrm{~mm}$ (optimum) \\
\hline Gap between Feed strip width and slot1(1 side=G) & 0.5 to $1.5 \mathrm{~mm}, 1 \mathrm{~mm}$ (optimum) \\
\hline
\end{tabular}

Where le is expansion in length of L-strip feed, $\mathrm{c}$ is velocity of light in vacuum, $\mathrm{Z} 0$ is characteristic impedance of feed and ereff is effective dielectric constant. The fringing capacitance between horizontal part of $\mathrm{L}$-strip and ground plane (Cf1) is calculated by putting $\mathrm{h}=\mathrm{h} 1+\mathrm{h} 2$ and the two capacitances involving patch and horizontal part of L-strip (both Cf2) is calculated by putting $\mathrm{h}=\mathrm{h} 3$. Fringing capacitance between patch and Lstrip is calculated using equations (4) and (5), ignoring curvature of patch. The capacitance due to vertical electric field between horizontal part of L-strip and patch is calculated as

$$
\mathrm{C} 3=\varepsilon \mathrm{r \varepsilon oYoWs} / \mathrm{h} 3
$$

The equivalent circuit of L-strip fed circular micro strip antenna is shown in fig. 2. The structure contains a series RLC resonant circuit in series with a parallel RLC resonant circuit. The parallel RLC circuit is equivalent of circular micro strip antenna. The resonance resistance $\mathrm{Rp}$ of patch, antenna capacitance $\mathrm{Cp}$ and inductance Lp are calculated by Stuart A. Long, Liang C. Shen, Mark D. Walton and Martin R. Allerding [9] and is given as

$$
\begin{aligned}
& \mathrm{R}_{\mathrm{p}}=\mathrm{J}_{\mathrm{n}}{ }^{2}\left(\mathrm{k}\left(\mathrm{a}-\mathrm{y}_{\mathrm{o}}\right)\right) /\left[\mathrm{G}_{\mathrm{t}} \mathrm{J}_{\mathrm{n}}^{2}\{\mathrm{ka}\}\right] \\
& \mathrm{C}_{\mathrm{p}}=\mathrm{Q}_{\mathrm{T}} /\left\{2 \pi \mathrm{f}_{\mathrm{res}} \mathrm{R}_{\mathrm{p}\}} \quad(10) \mathrm{L}_{\mathrm{p}}=\mathrm{R}_{\mathrm{p}} / 2 \pi \mathrm{f}_{\mathrm{res}} \mathrm{Q}_{\mathrm{T}}\right.
\end{aligned}
$$

Where QT is total quality factor, GT is total conductance of patch of radius a incorporating radiation loss, conduction loss and dielectric loss [22] and fres is resonant frequency of patch [22].

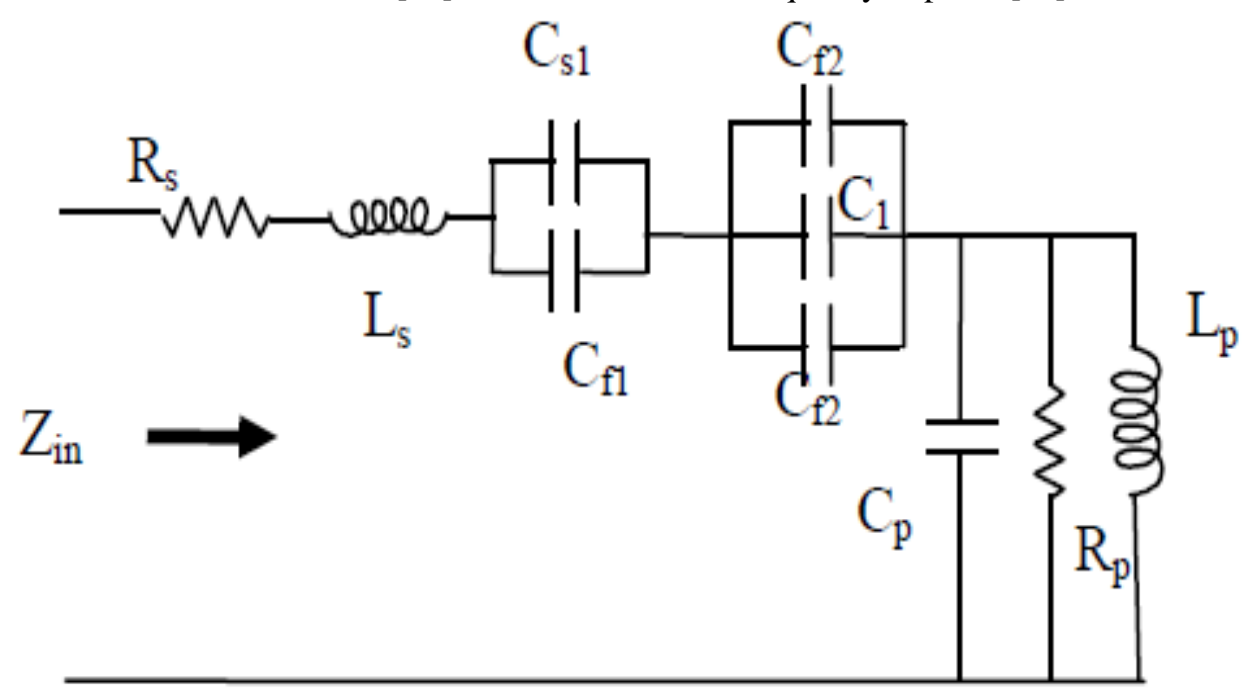

Fig.2 equivalant circuit of circular patch

$$
\begin{aligned}
\mathrm{Zp} & =\frac{1}{\left\{\frac{1}{\mathrm{Rp}}+\mathrm{j} \omega \mathrm{Cp}+\frac{1}{\mathrm{j} \omega \mathrm{Cp}}\right\}} \quad(10) \quad \mathrm{ZL}=\mathrm{Rs}+\mathrm{j} \omega \mathrm{Ls}+\frac{1}{\mathrm{j} \omega \mathrm{Ctotal}} \\
\mathrm{Zin} & =\mathrm{Rs}+\mathrm{j} \omega \mathrm{L}+\{1 / \mathrm{j} \omega \mathrm{Ctotal}\}+1 /\{((1 / \mathrm{Rp})(\mathrm{j} \omega \mathrm{Cp})+(1 / \mathrm{j} \omega \mathrm{Lp}))\}
\end{aligned}
$$

where Ctotal is total capacitance arising due to L-strip (i. e. C1, Cs1, Cf1, and Cf2) and is calculated as

$$
\text { Ctotal }=\frac{[(\mathrm{C} 1+2 \mathrm{Cf} 2)(\mathrm{Cs} 1+\mathrm{Cf} 1)]}{\{(\mathrm{C} 1+2 \mathrm{Cf} 2+\mathrm{Cs} 1+\mathrm{Cf} 2)\}}
$$

Where Rs, Ls, Ctotal, Zp are resistance, inductance of vertical part of L-strip, capacitance due to horizontal part of L-strip and patch impedance. Another impedance (ZL) may be defined for L-strip incorporating series combination of resistance Rs, inductance Ls, and capacitance Ctotal. 
Design and Analysis of Proximity Coupled Circularly Polarised Micro Strip Antenna with...

\subsection{Slot Loaded L-Strip Fed CMSA}

When a slot is cut in the L-strip fed circular micro strip patch, a series inductance (L'p) and a series capacitance (C'p) is introduced in the circuit. A capacitive (Cc) coupling is taken between modified circuit, which is shown in Fig. 3, and original resonance circuit due to small slot width. Thus total input impedance of the circuit is given as

$$
\begin{gathered}
\text { Zin }=R s+j \omega L s+\{1 / j \omega C \text { total }\}+Z p 2\left\{\left(\frac{\left(Z p 1+\frac{1}{j \omega C C}\right)}{Z p 2}+Z p 1+\left(\frac{1}{j \omega L p}\right)\right)\right\} \\
Z p 1=1 /\left(R p+j \omega L p+\frac{1}{j \omega C p}(15)\right. \\
C C=\left(C p+C^{\prime} p\right)+\sqrt{ }\left(C p+C^{\prime} p\right)\left(C p+C^{\prime} p(1-1 / \sqrt{ } C k)\right)
\end{gathered}
$$

coupling capacitance $\mathrm{Ck}=1 / \sqrt{ } \mathrm{Q} 1 \mathrm{Q} 2(18)$ and $\mathrm{Q} 1$ and Q2 are quality factors of original structure and slotted structure respectively. The equivalent circuit of L- strip fed circular micro strip antenna without parallel slots is shown in fig- $2 . \mathrm{Z}_{\mathrm{in}}=\mathrm{Z}_{\mathrm{p}}+\mathrm{Z}_{\mathrm{L}}$. Where $\mathrm{Zp}$ and $\mathrm{ZL}$ are given as The $\mathrm{R}$ 'p , $\mathrm{L}$ 'p and $\mathrm{C}$ 'p are calculated by taking equivalent RMSA for CMSA. The input impedance of the patch with parallel slots can be given from $[18,20]$.

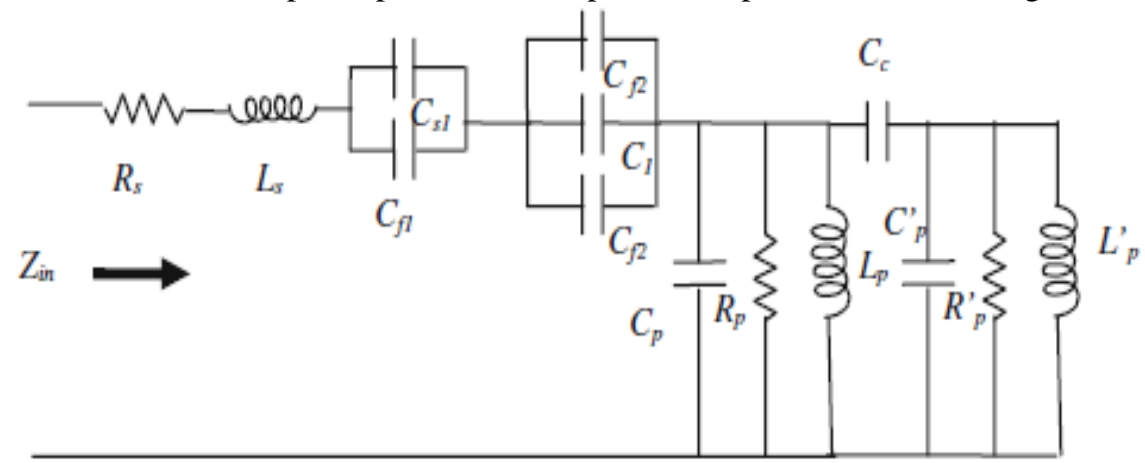

Fig.3 Equivalant circuit of circular patch with any of slots

The calculation of patch impedance is done using formula given in [20-22] hence the equivalent circuit of cross slot loaded L-strip fed circular microstrip antenna may be given from fig.3.

$$
\begin{gathered}
\mathrm{R}^{\prime} \mathrm{p}=\frac{\cos ^{2} \pi y \mathrm{y}}{2 \mathrm{a}} / 2\left(\mathrm{G}^{\prime} 1+\mathrm{G}^{\prime} 12\right) \\
\mathrm{G}^{\prime} 1=\frac{1}{120 \pi^{2} \int_{0}^{\pi} \frac{\sin ^{2}(\mathrm{~K} 2 \mathrm{a} \cos \theta)}{\cos ^{2} \theta} \sin ^{3} \theta \mathrm{d} \theta} \\
\mathrm{G}^{\prime} 12=\frac{1}{120 \pi^{2} \int_{0}^{\pi} \frac{\sin ^{2}(\mathrm{~K} 2 \mathrm{a} \cos \theta)}{\cos ^{2} \theta} \sin ^{3} \theta \mathrm{Jo}(\mathrm{k} 2 \mathrm{asin} \theta) \mathrm{d} \theta}
\end{gathered}
$$

where $\mathrm{k} 2$ is wave number at resonance frequency of modified resonance circuit. And L'p $=\mathrm{Lp}+\nabla \mathrm{L}$ and $C^{\prime} p=C p \nabla C / \nabla C+C p$ respectively. Where $\nabla$ Land $\nabla C$ are:

$$
\begin{gathered}
\nabla \mathrm{L}=\frac{\mathrm{Z} 02+\mathrm{Z} 01}{\left(16 \pi \text { fres } \cos ^{2}\left(\frac{\pi \mathrm{y} 0}{2 \mathrm{a}}\right)\right)} \tan \left(\frac{\pi \text { fresls }}{\mathrm{c}}\right) \quad(21) \text { and } \mathrm{Z} 01=\frac{120 \pi}{\left\{\left(\frac{\mathrm{w} 1}{\mathrm{~h}}\right)+(1.393)+0.667 \ln \left(\frac{\mathrm{w} 1}{\mathrm{~h}}+1.44\right)\right\}} \\
\mathrm{Z} 02=120 \pi /\left\{(\mathrm{w} 2 / \mathrm{h})+(1.393)+0.667 \ln \left(\frac{\mathrm{w} 2}{\mathrm{~h}}+1.44\right)\right\}
\end{gathered}
$$

Where $\omega 1=\mathrm{a}-\mathrm{Pn}-\frac{\mathrm{s}}{2}$ and $\omega 2=\mathrm{a}+\mathrm{Pn}-\frac{\mathrm{s}}{2}$ and

$$
\begin{gathered}
\nabla C=\mathrm{ls}\left[\frac{\varepsilon 0}{\pi} \ln \left\{\frac{2\left(1+\sqrt[4]{1-2 \mathrm{x}^{2}}\right)}{1}-\sqrt[4]{1-2 \mathrm{x}^{2}}\right\}+\frac{\varepsilon 0 \varepsilon \mathrm{r}}{\pi} \ln (\cot \pi \mathrm{s} / 4 \mathrm{~h})\right] \\
\left.+0.65 \sqrt{\operatorname{\varepsilon reff} \frac{1}{\mathrm{cZ} 0}\left(\left(0.02 \mathrm{~h} \sqrt{\frac{\mathrm{Er}}{\mathrm{s}}}\right)\right.}+1-1 / \varepsilon^{2}\right),
\end{gathered}
$$


where $\mathrm{x}=(s / h) /\{(s / h)(2 \omega / h)\}$, ls is the lenth of slot and $\mathrm{s}$ is width of slot.

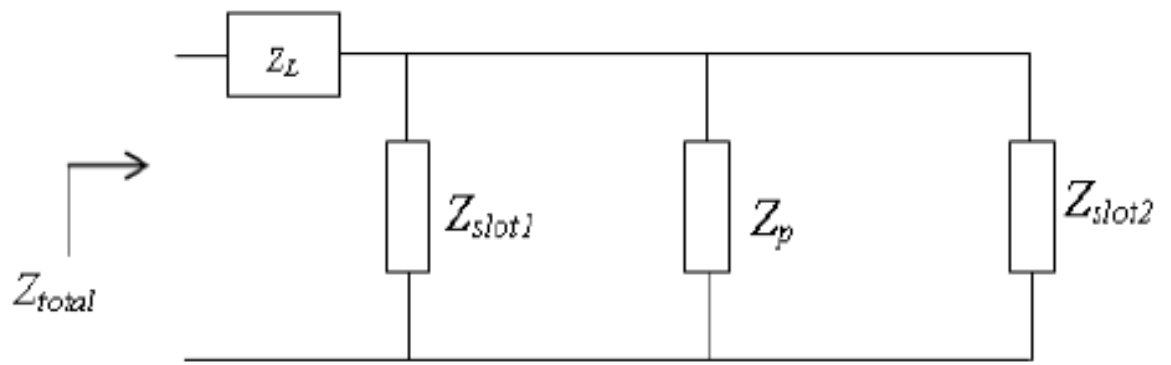

Fig. 4. Equivalent circuit of Asymmetric Cross slot Loaded L strip

Proximity Coupled Circular micro strip antenna have input impedance of parallel slot loaded micro strip antenna is given using fig. 3 and fig. 4 as

$$
Z_{\text {total }}=Z_{L}+\frac{Z_{\text {slot } 1} Z_{\text {slot } 2} Z_{p}}{\left(Z_{p} Z_{\text {slot } 1}+Z_{p} Z_{\text {slot } 2}+Z_{\text {slot } 1} Z_{\text {slot } 2}\right)}
$$

Where Zslot1 and Zslot2 are the impedance of slot1 and slot2 respectively and given in [23]. The design specification for the slot loaded circular disk patch antenna is given in table-I.

\section{Result And Discussion}

The L-strip proximity coupled micro strip CMSA is analyzed and the grades are compared among the ones acquired by Y. X. Guo, K. M. Luk and K. F. Lee [11]. The variation of input impedance with frequency for different horizontal length of L-strip of proposed structure has also been compared in that work. The capacitive nature of antenna augments with horizontal length of L-strip. The resonance resistance diminishes as open end of L-strip progress towards centre of patch. This designates that open end is operational as feed point. Matching improves with the horizontal length of L-strip variation. At identical time, bandwidth reduces due to increased quality factor of the structure. It is apparent that bandwidth reduces with increase in $\mathrm{Li}$ at constant value of $\mathrm{h} 2$. Feed location at open end of L strip and capacitive reactance by horizontal L strip to patch overlap has been adjusted to balance both input impedance as well as BW. It is clear from the graphs that the antenna posses' two resonant frequencies extremely close to each one resulting in a broad band instead of dual band feature. The superior value of resonant frequency is natural frequency of L-strip fed CMSA and inferior value is due to enlarged path of current in slotted CMSA. Here base cmsa is said to be the circular structure (radius $=17 \mathrm{~mm}$ ) without any slot and slot 2 is a slot shown over strip line feed and an optional slot is revealed at Pn distance in y axis length as of the first slot by (17x4). It is kept as optional slot as it is used in literature [20] for similar dimensions. Slot inset2 is kept only for optional slot with inset similar look slot over feed line in circular patch. Wherever inset phrased it is due to well-known structure of micro strip line feed by inset scheme. The inset feed in narrative is made at same layer of patch except here it is named only due to geometrical symmetry from the view point if seen from the top (towards $\mathrm{z}$ direction).

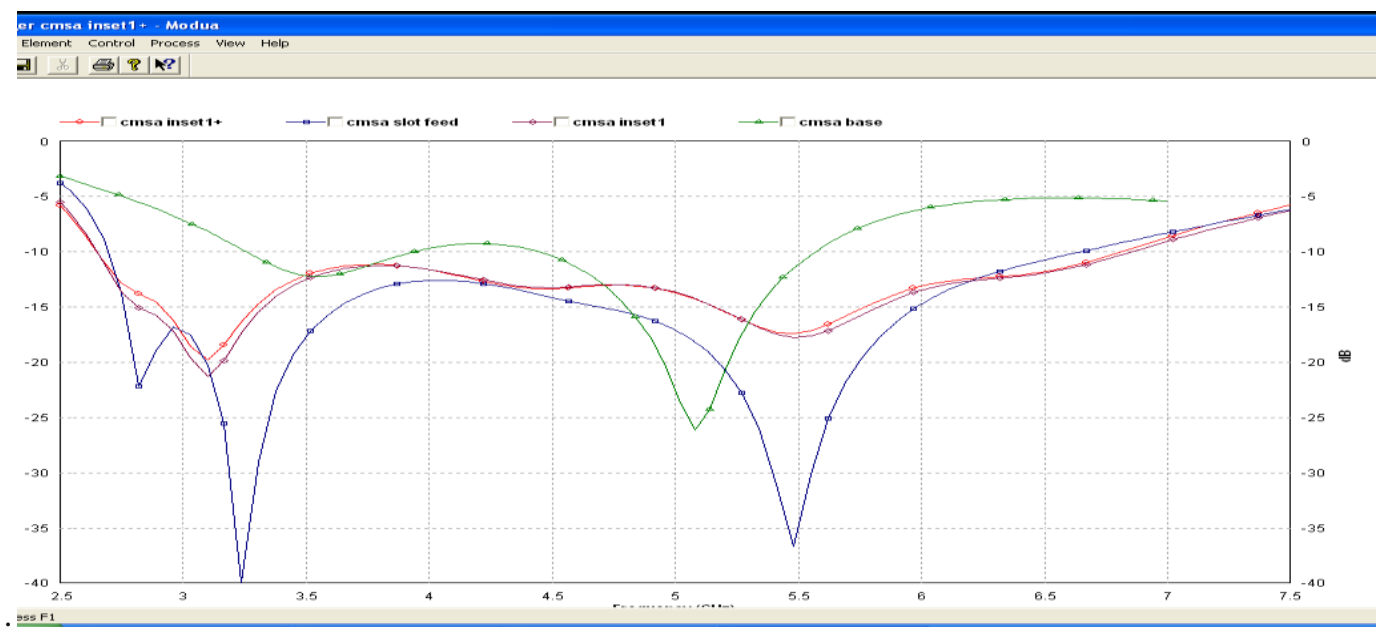

Fig. 5. Reflection Coefficient vs frequency comparative study of a circular patch with /without slots

Figure 5 shows variation of reflection coefficients for different value of slot lengths. It is observed that as the length of slot increases, the path of current lines increases. This causes shift in resonant frequency of the structure towards lower side. Total range of frequency for CMSA comes at (4.45-5.58 and 3.35-3.85) GHz. The 
simulated result shows three resonances- first due to patch, second due to L-strip and third due to slots. The simulated result exhibits dual band and broadband characteristic at the same time. In fact the resonance due to the two slots are merged together giving almost flat response around 3.5 to $5 \mathrm{GHz}$, which has more flat range than other tried structure as shown.
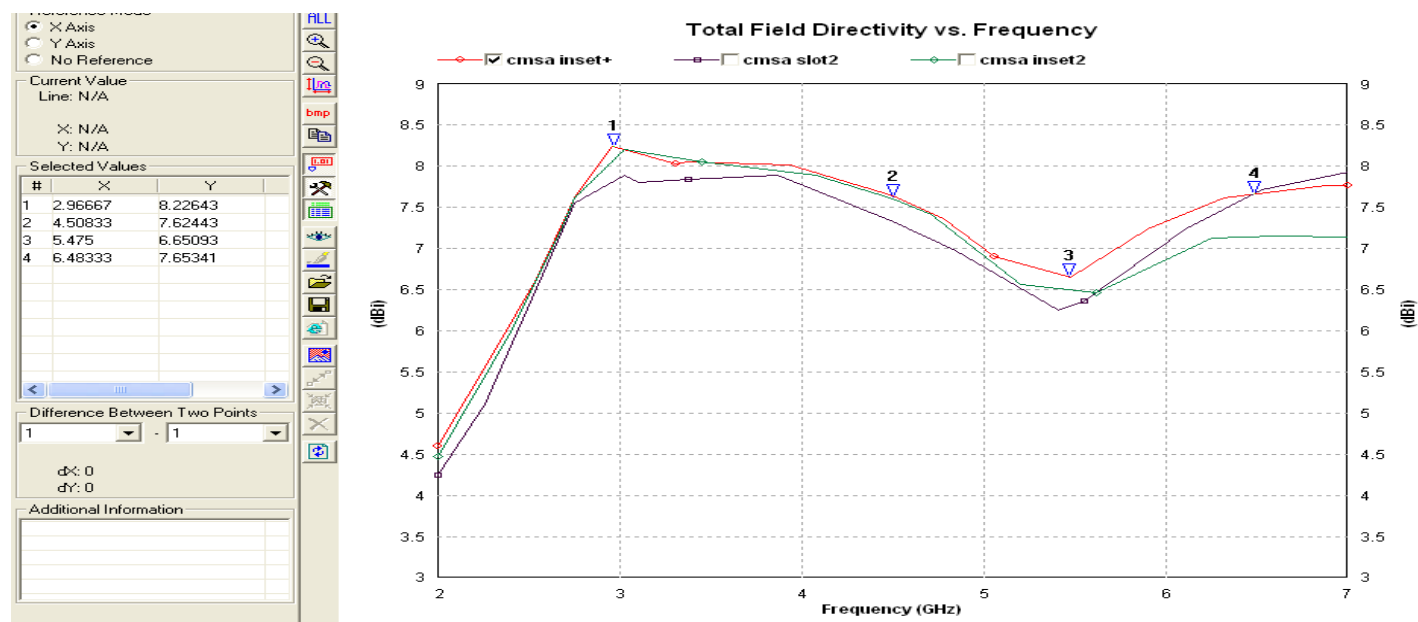

Fig. 6. Directivity vs frequency comparative study of a circular patch with /without slots

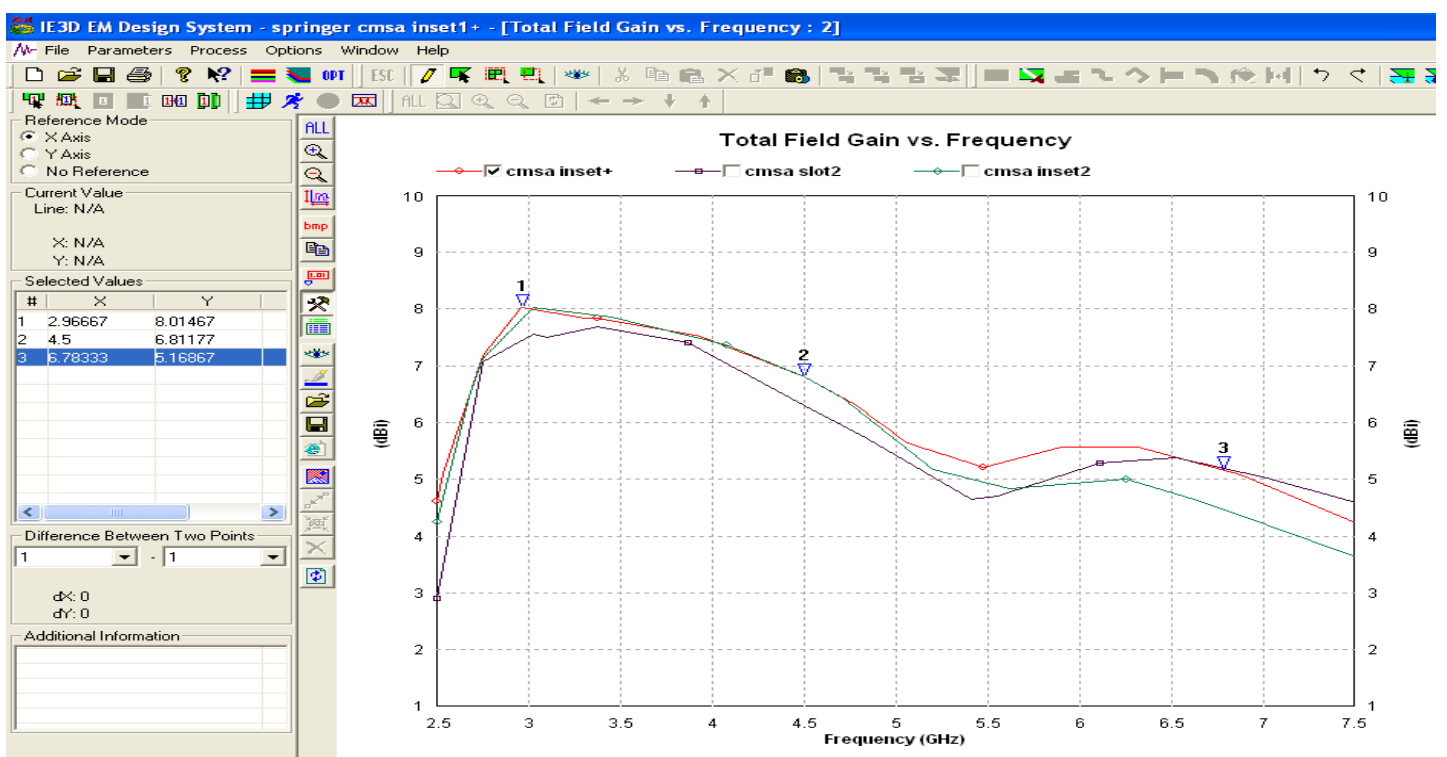

Fig. 7. Gain vs frequency comparative study of a circular patch with /without slots

Thus by slots total range comes as (2.70-6.15) GHz for two inset slots (2.62-6.78) GHz where first structure comes with better reflection coefficient (up to $-43 \mathrm{~dB}$ ) and second with broader range (S11=-19dB). Total improvement maximum resulted as $(97.02-39.21=57.81) \%$.

Further on the observation is seen for basically $2.96 \mathrm{GHz}$ and $4.5 \mathrm{GHz}$ (as these frequency were observed for circular polarisation resonance) and also for lowest to highest values of different radiation attributes. Figure 6 shows directivity of antenna for different combination of slots. It comes up to $8.22 \mathrm{~dB}$ at 2.96 $\mathrm{GHz}$ and $7.62 \mathrm{db}$ at $4.5 \mathrm{GHz}$ with lowest value of 6.65 at $4.5 \mathrm{GHz}$ within the concerned range. Figure 7 shows variation of gain with frequency. It comes up to $8.02 \mathrm{~dB}$ at $2.96 \mathrm{GHz}$ and $6.82 \mathrm{db}$ at $4.5 \mathrm{GHz}$ with lower values at higher frequencies up to 5.15 at $6.78 \mathrm{GHz}$ within the concerned range. Figure 8 shows that radiation efficiency is greater than $62 \%$ in all the bandwidth of the antenna. It comes up to $97.45 \%$ at $2.96 \mathrm{GHz}$ and $86.73 \%$ at 4.5 $\mathrm{GHz}$ with lower values at higher frequencies up to $62.78 \%$ at $6.78 \mathrm{GHz}$ within the concerned range. At most of frequency it remains higher which shows low power being return from antenna at feed port and the low losses stirring in the antenna. 
Design and Analysis of Proximity Coupled Circularly Polarised Micro Strip Antenna with...

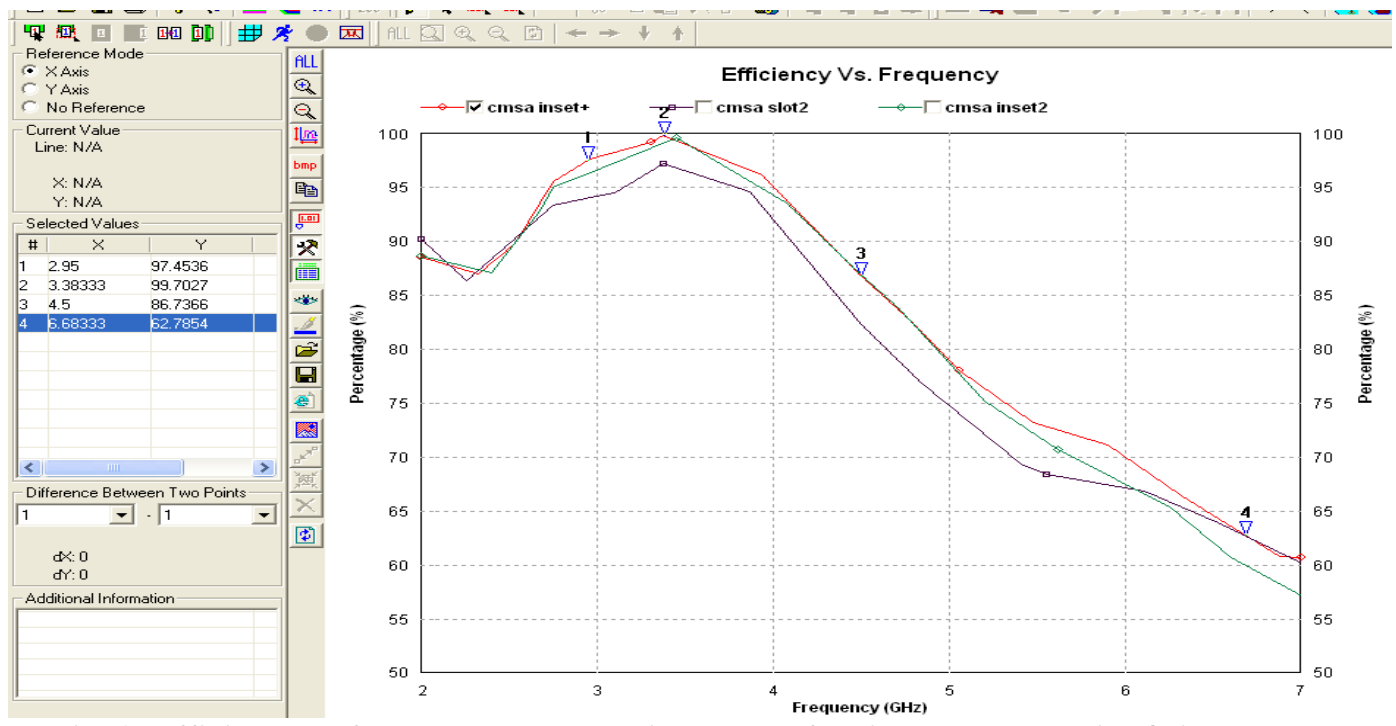

Fig. 8. Efficiency vs frequency comparative study of a circular patch with /without slots

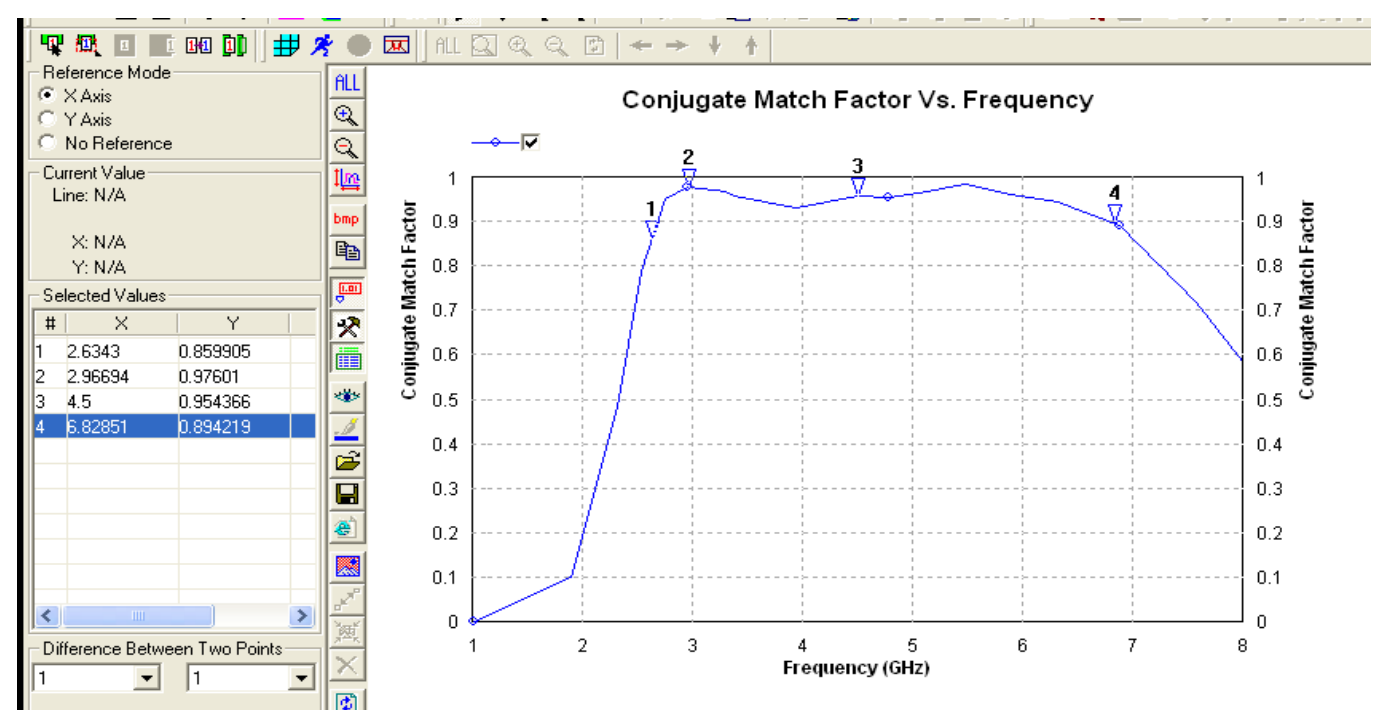

Figure 9 Conjugate Impedance matching vs frequency for cmsa inset+

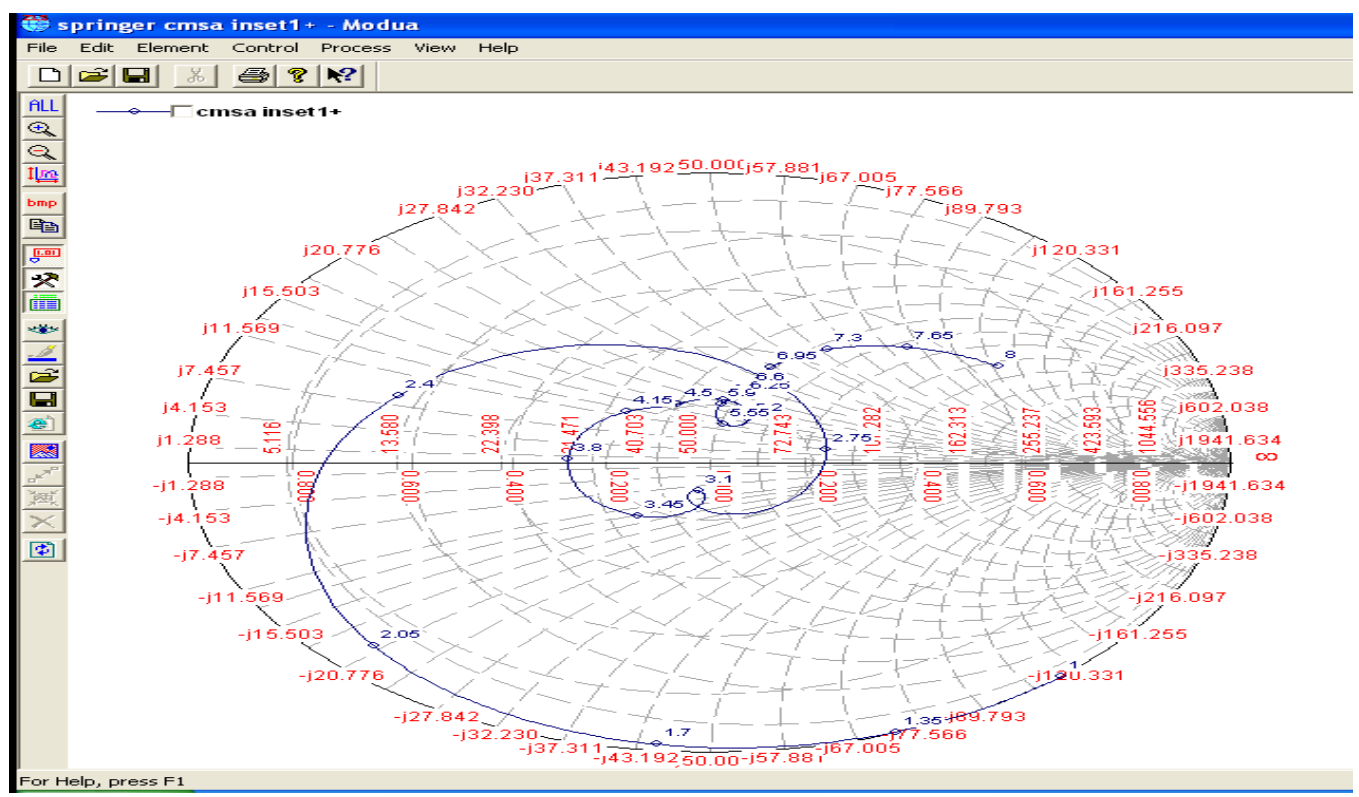

Fig.10. smith chart for CMSA inset+ 
The fig.9 shows that reactance matching at CMSA inset1+ which results as cancellations of capacitive loading due to patch and horizontal feed strip with respect to inductance by vertical feed length, with linear scale as $1=$ conjugate match factor being the best match for reactance load so resistive load remains to match $50 \Omega$ feed strip to transfer maximum power in broadside direction by patch the plot of axial ratio with respect to frequency at broadside of antenna. From the figure 10 it is shown that smith chart pattern which exhibits all variation of impedance throughout the range of frequency in operation. In lower ranges capacitive load of slot and patch is found to dominate and radiation is found in the end fire directions and at higher frequency feed gap radiation with inductive load below patch is dominating which goes to match the load too. It also leads frequency variation analysis of VSWR2:1 range.

Figure 11 is showing that axial ratio bandwidth is $6.08 \%(\mathrm{AR}<3 \mathrm{~dB})$ in the frequency range of 2.86$3.06 \mathrm{GHz}$ and bandwidth is $6.9 \%(\mathrm{AR}<3 \mathrm{~dB})$ in the frequency range of $4.338-4.654 \mathrm{GHz}$. The circular polarization can generally be obtained only for narrow band of frequencies; hence it is vital to have accurate prophecy for the measurement of the patch and slot.

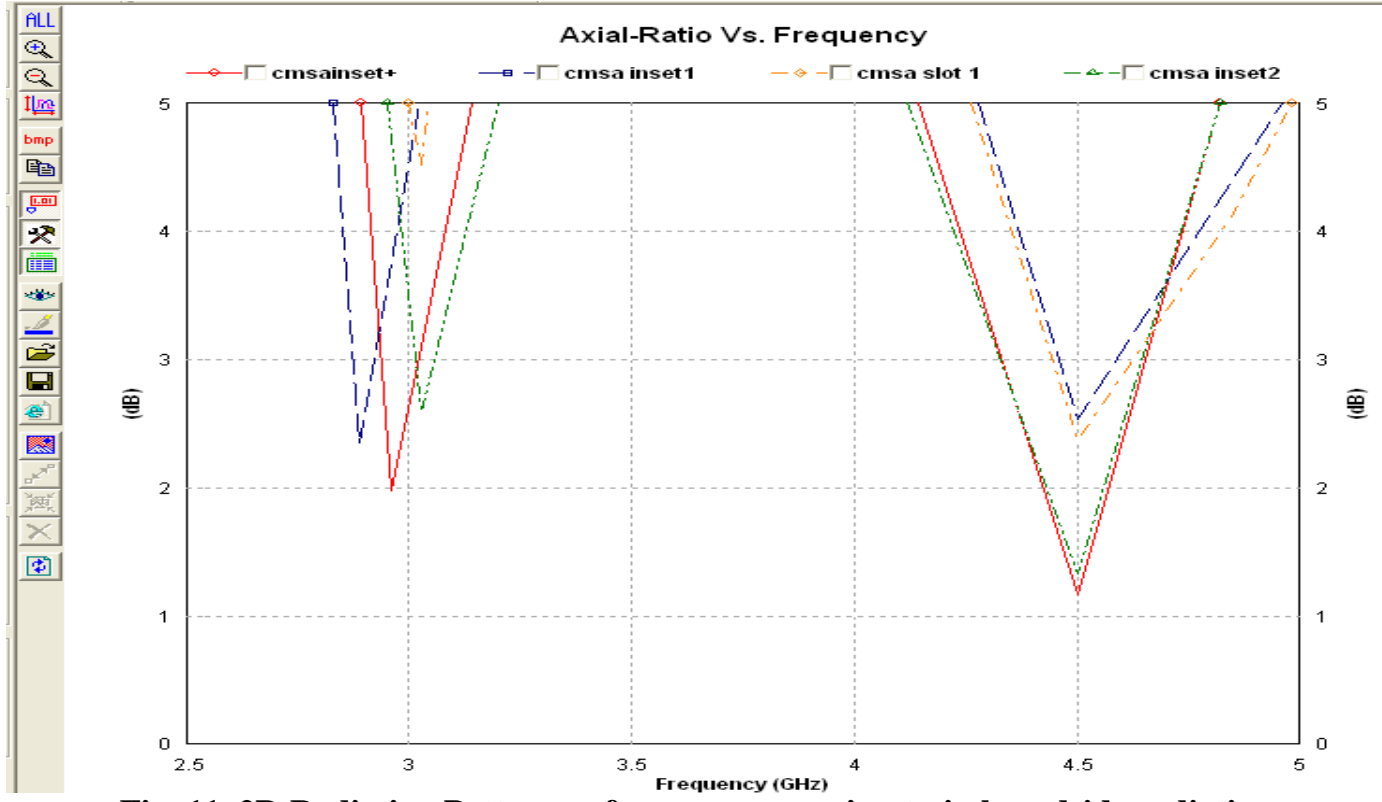

Fig. 11. 2D Radiation Pattern vs frequency cmsa inset+ in broadside radiation

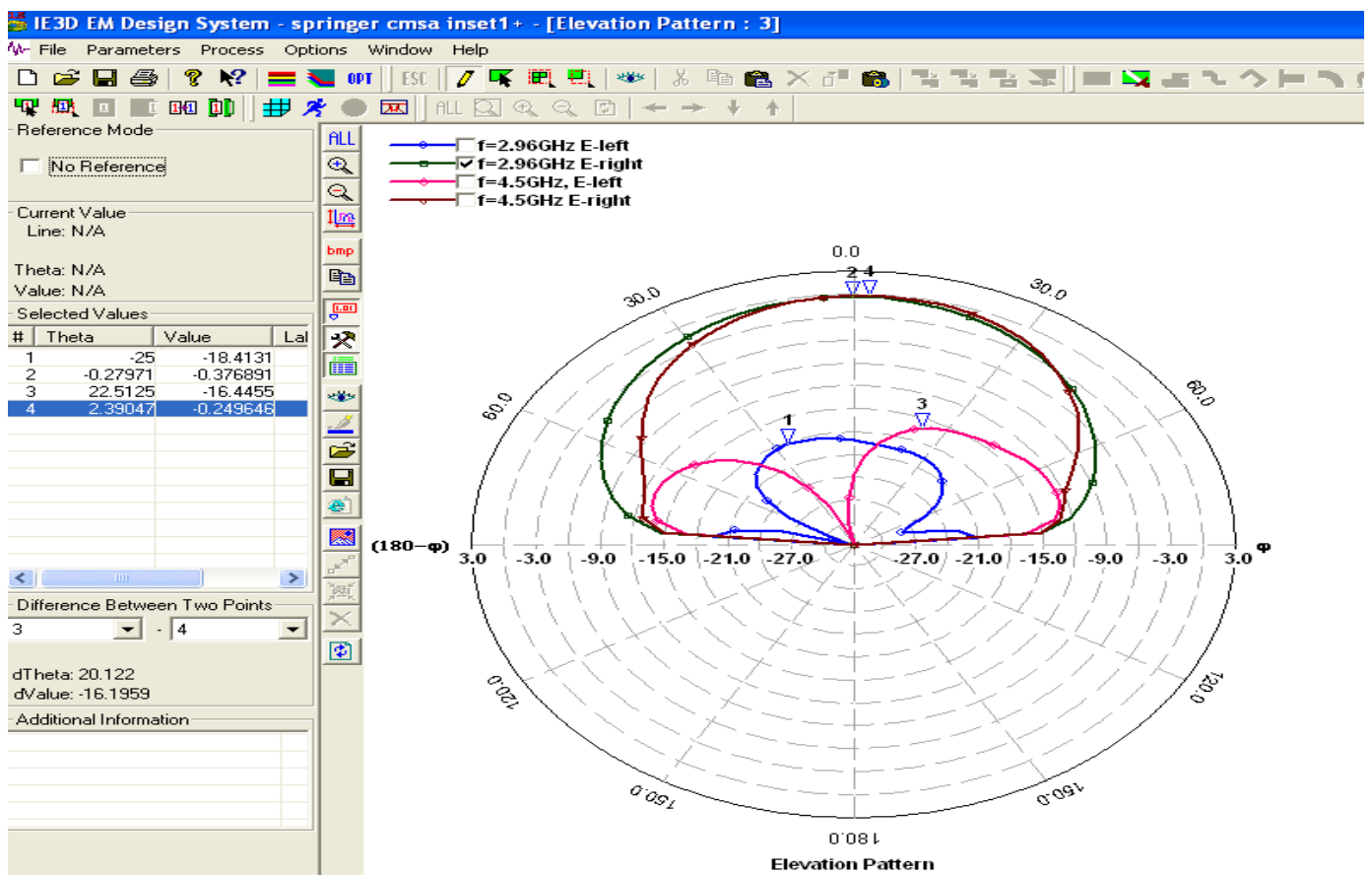

Fig. 12. Elevation pattern for circular polarisation (RHCP and LHCP) for CMSA inset + 
Figure 12 is showing that circular polarisation achieved was dominating at RHCP than to LHCP at both $2.96 \mathrm{GHz}$ and $4.5 \mathrm{GHz}$ of resonance $\mathrm{CP}$ frequency. Where it can also be seen that $\mathrm{PG}=$ peak gain normal to patch and $\mathrm{AG}=$ average gain at broadside direction with showing the $94^{\circ}$ and $82^{\circ}$ beam width respectively for lower and higher CP resonance.

\section{Conclusion}

This paper describes the results of asymmetric parallel built slots loaded wide band circularly polarized micro strip antenna for different wireless applications. The parallel slots create two orthogonal modes which operate very close in frequency and through merger of resonance, help to achieve wideband impedance bandwidth and also provide circular polarization within the range of maximum radiation and in broadside. The proposed antenna design has improved $-10 \mathrm{~dB}$ reflection coefficient bandwidth up to $57.8 \%$ [20] and due to asymmetrical and parallel slots 2 axial ratio bandwidths are about $6.08 \%$ and $6.9 \%$. The antenna designed is useful for mobile and IMT as well as lower satellite communication ranges.

\section{Acknowledgment}

The authors would like to thank Mr. Abhinav Bhargav (Asst. Prof.) and Prof. Samrat Gosh (H.O.D.) of the Department of Electronic Engineering, G.G.I.T.M. Bhopal, INDIA for providing helpful suggestions in process of work and antenna design lab with IE3D software availability in studies of the antenna designing.

\section{Reference}

[1]. D. M. Pozar, "An update on microstrip antenna theory and design including some novel feeding techniques," IEEE Antenna and Propagation Society, vol. 28, no 5,pp 5-9 1986 .

[2]. E Chang, S. A. Long and W. F. Richards, "An experimental investigation of electrically thick rectangular microstrip antenna," IEEE Transactions on Antennas and Propagation, Vol. 34, No. 6, pp. 767- 772,1986.

[3]. R. Q. Lee K. F. Lee and J. Bobinchak, "Characteristics of a two layer electromagnetic rectangular patch antenna," Electronics letters, Vol. 23, No. 20, pp. 1070-1072,1987.

[4]. L. I. Basilio, M. A. Khayat, J. T. Williams and S. A. Long, "The Dependence of the Input Impedance on Feed Position of Probe and Microstrip Line-fed Patch Antennas," IEEE Trans. Antennas and Propagation, Vol. AP-49, pp. 45-47, Jan. 2001.

[5]. T. Samaras, A. Kouloglou, and J. N. Sahalos, "A note on the impedance variation with feed position of a rectangular microstrip antenna," IEEE Antennas and Propagation Magazine,

[6]. H. F. Pues and A. R. Van De Capelle, "An impedance matching technique for increasing the bandwidth of microstrip antenna," IEEE Antennas and Propagation Magezine, Vol 37, Issue 11, pp. 1345-1354, 1989.

[7]. Huynh, T. and K. F. Lee, "Single layer single patch wideband antenna, Electronics letters," vol. 31, no 16, pp 1310-1312, 1995. Vol. 46, pp. 90-92, April 2004.

[8]. A proximity fed circularly polarized microstrip patch antenna with a cross slot in the ground plane Kshitiz Agarwal(a), G.P. Rao(a), M.V. Kartikeyan(a), M.K. Thumm(b;c) (a) Department of Electronics \& Computer Engineering, Indian Institute of Technology Roorkee Roorkee 247 667, Uttaranchal, India (b) Forschungszentrum Karlsruhe, Institut fÄur Hochleistungsimpuls\{ und Mikrowellentechnik (IHM), Microwave and optical technology letters, vol.25, no.4, pp. 251-253, 2000.

[9]. Stuart A. Long, Liang C. Shen, Mark D. Walton and Martin R. Allerding, "Impedance of a Circular Disc Printed Antenna”, Electronics letters, Vol. 14, No. 21, 1978.

[10]. S. Shi, K. Hirasawa, and Z. N. Chen, "Circularly polarized rectangular bent slot antennas backed by a rectangular cavity," IEEE Transactions on Antennas Propagation, Vol. 49, No. 11, pp. 1517-1524, 2001.

[11]. F. S. Chang, K. L. Wong, And T. W. Chio, "Low-cost broadband circularly polarized patch, IEEE Transactions on Antennas Propagation, Vol. 51, No. 10, pp. 3006-3009, 2003.

[12]. H. Iwasaki, “A circularly polarized small-sized microstrip antenna with a cross-slot," IEEE Transactions on Antennas Propagation ,Vol. 44, No. 10, pp. 1399-1401,1996.

[13]. N. Herscovici, Z. Sipus, and D. Bonefacic, "Circularly polarized single fed wideband microstrip patch," IEEE Transactions on Antennas Propagation, Vol. 51, No. 6, pp. 1277-1280, 2003.

[14]. W.K.Lo, J. L. Hu, C.H. Chan, and K.M.Luk " L-Shaped probe-feed circularly polarized microstrip patch antenna with a cross slot," Microwave and optical technology letters, vol.25, no.4, pp. 251-253, 2000.

[15]. X. Ojng and M.Y.W. Chia, "Broadband annular dual-slot antenna for WLAN applications," IEEE AP-S Int Symp Digest , Vol. 2, 452-455, 2002 .

[16]. Manoj Kumar Meshram., "Analysis of L-strip proximity fed rectangular microstrip antenna for mobile base station,” Microwave and optical technology letters, vol.49, no.8, pp. 1817-1824, 2007.

[17]. Davatosh Guha, "Resonant frequency of circular microstrip antennas with and without air gap," IEEE Transactions on Antennas Propagation, vol. 49, no. 1, pp. 55-59, 2001

[18]. Analysis and Design of L-strip Proximity Coupled Circular Microstrip Antenna Ganga Prasad Pandey1*, Binod Kumar Kanaujia2, Surendra. K. Gupta3 and A. K. Gautam4, Journal of Microwaves, Optoelectronics and Electromagnetic Applications, Vol. 11, No. 1, June 2012

[19]. F. Abboud, J. P. Damiano and A. Papiernik, "A New Model for Calculating the Input Impedance of Coax-Fed Circular Microstrip Antennas with and without Air Gaps", IEEE Transaction on Antenna and Propagation, Vol. 38, No. 11, pp. 1882-1885, 1990.

[20]. Ganga Prasad Pandey, Binod Kumar Kanaujia, A. K. Gautam and Surendra K. Gupta, "Ultra-Wideband L-strip Proximity Coupled Slot Loaded Circular Microstrip antenna for Modern Communication Systems", Wireless Personal Communication, published on line june 09, 2012, DOI 10.1007/s11277-012-0684-5

[21]. Singh, P., and Kumar, D. 2011, L-strip Proximity fed Broadband Circular Disk Patch Antenna, International Journal of Microwave and Optical Technology, vol. 6, No. 2, (March 2011), pp. $64-69$

\section{Books:}

[22]. R. K. Huffman, Handbook of Microwave Integrated circuits, Artech House, Narwood, MA, 1987.

[23]. T. C. Edward, Foundation for Microstrip Circuit Design, john Wiley, 1983. 